\title{
Identification and evaluation of land use vulnerability in a coal mining area under the coupled human-environment
}

https://doi.org/10.1515/geo-2019-0006

Received Sep 17, 2018; accepted Dec 31, 2018

\begin{abstract}
Based on the coupled human-environment, and taking the Hegang coal mining area (Heilongjiang Province, China) as a research area, combined with RS and GIS technologies, from the perspectives of environmental exposure, sensitivity, and adaptive capacity, the analytic hierarchy process and expert consultation methods were used to establish the evaluation index system and weight. Then the mathematical model of vulnerability assessment was constructed, and the spatial analysis method was used to dynamically identify and evaluate the vulnerability of land use in the study areas in 1994, 2006, 2010, and 2014. The results show that: 1) the vulnerability of land use shows an increasing trend from 1994-2014, and most of the landscape types show a strong dominant vulnerability; 2) the adaptive capacity of land use gradually became unstable under the influence of human-land coupling, and the land-use environment showed the trend of transformation from potential vulnerability to extreme vulnerability under the dual action of sensitivity and exposure; 3 ) from the type of land use, the vulnerability of coal mine land and unutilized land was relatively prominent. The two landscape types were mostly distributed in severe or extremely vulnerable areas over the past 20 years, indicating a greater degree of interference. The results provide the decision-making basis for the scientific planning and management of the land, and provide guidance for ecological restoration and environmental protection.
\end{abstract}

Keywords: Land use vulnerability; Coal mining area; Coupled system of human-environment; Exposure; Sensitivity; Adaptive capacity

\footnotetext{
^Corresponding Author: Yunlong Yao: College of Wildlife Resources, Northeast Forestry University, Harbin 150040, China; Email: yl.yao@163.com; Tel.: +8615146610297

*Corresponding Author: Dawei Xu: College of Architectural Engineering, Heilongjiang University of Science and Technology, Harbin 150022, China; Email: xdw_ysm@126.com; Tel.: +8613304637599
}

\section{Introduction}

Recent and continuing changes in climate have resulted in alterations to both human and natural systems across the globe, and the problem of ecological vulnerability is particularly prominent, necessitating adaptive measures by decision-makers acting at all levels of socio-ecological systems [1, 2]. In recent years, the concept of vulnerability has been studied and applied at different spatial scales and in a wide range of disciplines, such as in economic and social welfare studies [3], natural hazards effects [4], environmental studies [5, 6], and sustainability science and land patterns $[7,8]$. Ecological vulnerability refers to the vulnerability of ecosystems and their components to internal and external disturbances. Research on ecological vulnerability has become a hot topic in the study of global change and sustainable development $[9,10]$.

In the application of technology, RS and GIS have been widely used in various fields, such as land use and vulnerability studies in mining areas, mainly including mine monitoring and environmental impact vulnerability [11], land use type distribution and vulnerability assessment [12, 13], and the evaluation of soil fertility in mining areas [14]. Demirel et al. [15] used GIS classification to identify, quantify, and analyze the spatial pattern of landscape changes caused by mining activities in Turkey. Karan et al. [11] used a support vector machine (SVM) and maximum likelihood to evaluate and monitor the change of land cover in opencast coal mines, and laid the foundation for vulnerability assessment. Vulnerabil-

Lei Wang: College of Architectural Engineering, Heilongjiang University of Science and Technology, Harbin 150022, China; College of Landscape Architecture, Northeast Forestry University, Harbin 150040, China; College of Agricultural and Life Sciences, University of Wisconsin, Madison, 53706, United States of America; This author contributed equally to this study

Yunna Jia: Henan Urban and Rural Planning and Design Research Institute Co., Ltd, zhengzhou 450000, China; This author contributed equally to this study 
ity evaluation is the key to scientifically identify the origin mechanism and change rule of ecosystem vulnerability. Among them, the analytic hierarchy process (AHP), principal component analysis (PCA), and comprehensive evaluation are more extensive, and some foreign scholars also apply multi-scale, visualization, VSD models [16, 17], and other methods for vulnerability assessment. However, it is still a challenge to establish a suitable land vulnerability assessment system for special areas (especially for coal mines) [18].

Land use and land cover (LULC) not only reflects human activity, it also impacts climate [19, 20]. Land resources serve as the material basis and economic product of the important human existence and development, it is estimated that over $45 \%$ of the Earth's surface is affected by artificial changes in LULC from its natural state [21, 22]. The transformation of land by human activities can disrupt biogeochemical cycles [23] and influence the vulnerability of people and infrastructure to various natural hazards [24]. Although there are relatively more related studies on vulnerability, there are few studies on the vulnerability of land use in coal-based cities based on the coupled human-environment. A great deal of evidence shows that the interference of the coupled human-environment to the structure and function of land in coal mines leads to land degradation [25], serious agricultural land pollution and the changing margins of land cover [26]. Although there is no clear conceptual model for coupling system vulnerabilities, most researchers generally agree that exposure, sensitivity, and adaptive capability are the components of system vulnerability $[27,28]$, and based on the human-coupled vulnerability theory [29], they established a vulnerability assessment framework for land systems responding to multiple disturbances.

Hegang is one of four major coal resource bases in Heilongjiang Province of China. Long-term coal mining has led to serious damage to the structure and function of the land. The trend of land degradation is gradually changing. It has become a typical and severely damaged ecosystem. Based on the 20 years of 1994-2014 remote sensing images and statistical data, combined with RS and GIS technology, this paper constructs the evaluation system and mathematical model of vulnerability of land use from the aspects of ecological, economic, and social aspects of exposure, sensitivity, and adaptive capacity, and conducts vulnerability studies on time and space scales. Thus, we reveal the dynamic change rule of vulnerability in the Hegang coal mine area under the coupling of humans and the Earth, with an aim to provide guidance for ecological environment construction and rational utilization of land in Hegang, and finally achieve sustainable development.

\section{Materials and methods}

\subsection{Study Site}

Hegang is located in the hilly region of the eastern foot of the Little Xing'an Mountains and the plains at the junction of the Songhua River and Heilongjiang River, in Northern China $\left(47^{\circ} 03^{\prime} 30^{\prime \prime}-48^{\circ} 21^{\prime} 00^{\prime \prime} \mathrm{N}\right.$ and $129^{\circ} 39^{\prime} 50^{\prime \prime}-132^{\circ}$ $31^{\prime} 00^{\prime \prime}$ ), as shown in Figure 1. The coal mining area is located in the northwestern region of Hegang, selected as a typical research area. The climate of Hegang City is affected by the temperate continental monsoon, it is cold and dry in winter and warm and rainy in summer. The average annual temperature is $1.0-4.6^{\circ} \mathrm{C}$, the average annual frost-free period is about 125 days, and the average annual rainfall of about $608.5 \mathrm{~mm}$. The study area as a whole showed a low trend in the south and high in the south, with the hills in the north and the plains in the south.

\subsection{Data Sources}

The data are mainly from the United States Geological Survey (USGS) and geospatial data cloud in 1994, 2006, 2010, and 2014. From the Hegang TM/ETM and OIL remote sensing images, we chose the remote sensing image for September because the features of this period are vivid and easy to distinguish and analyze (Table 1). The classification results were obtained by field sampling data and remote sensing interpretation, showing that the image classification accuracy rate of land use types in the four periods reached more than $95 \%$. Spatial classification and statistical analysis of land use types in the coal mining area are carried out through a GIS spatial analysis module.

Other information data are from the Heilongjiang Statistical Yearbook, Hegang Statistical Yearbook, China Urban Statistical Yearbook, Hegang Municipal District vector boundaries, Google maps, and field sampling data.

\subsection{Methods}

\subsubsection{Land use classification based on a support vector machine}

A support vector machine (SVM) is a supervised nonparametric statistical learning technique, therefore, there is no assumption made on the underlying data distribution [30]. Compared with other classification techniques, an SVM classifier is a powerful supervised classification method that can solve some practical problems, such as 


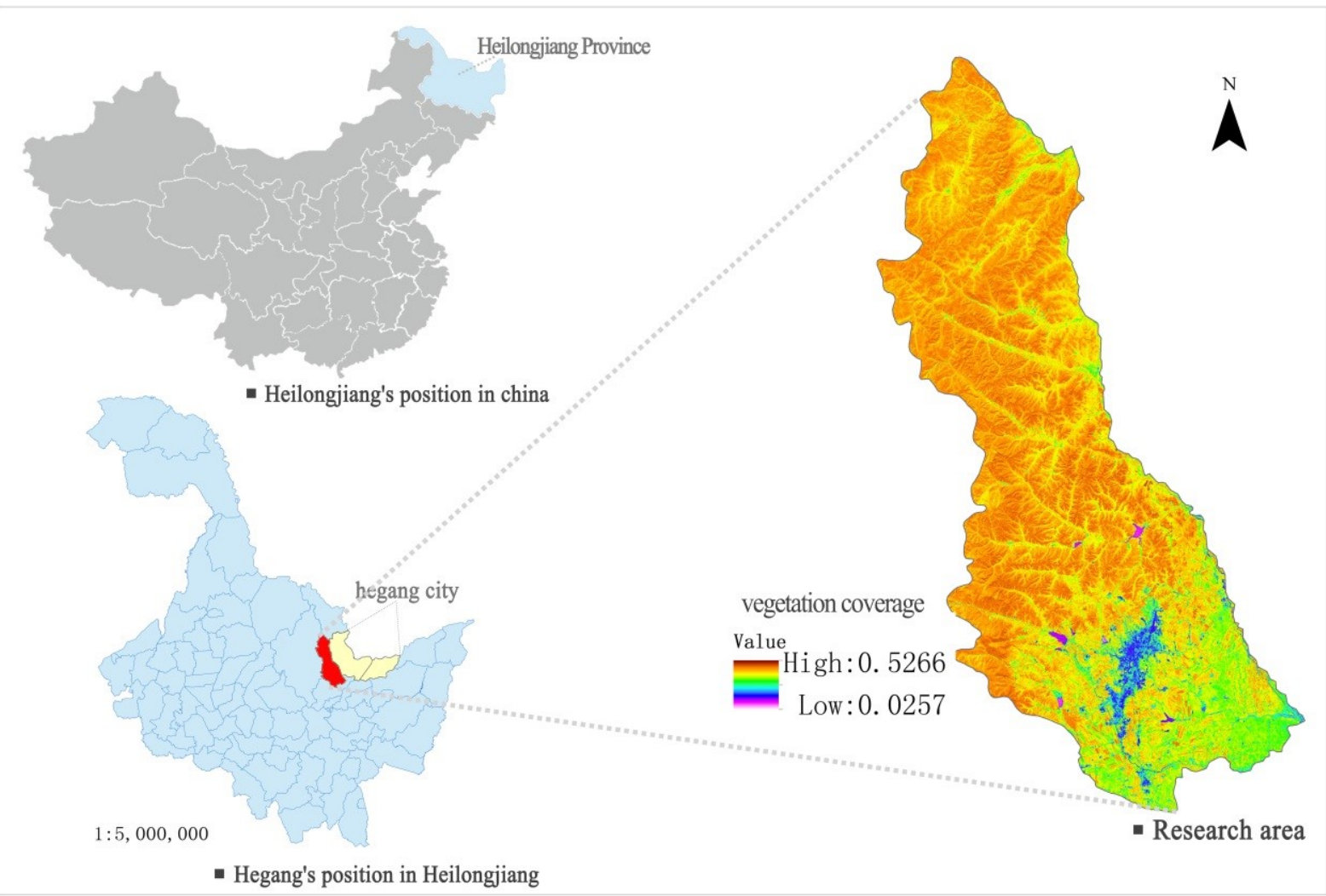

Figure 1: Location of the research area.

Table 1: List of remote sensing images.

\begin{tabular}{ccccc}
\hline Sensor & Date & Image data identification & Center longitude & Center latitude \\
\hline Landsat4-5 & $1994-9-12$ & LT51160271994255HAJ00 & 129.9270 & 47.4668 \\
Landsat7 & $2001-9-07$ & LE71160272001250EDC00 & 129.9361 & 47.4510 \\
Landsat7 & $2001-9-14$ & LE71170272001257EDC00 & 128.9411 & 48.8680 \\
Landsat4-5 & $2006-9-29$ & LT51160262006272IKR00 & 130.0034 & 47.4515 \\
Landsat4-5 & $2010-9-08$ & LT51160262010251IKR00 & 129.9717 & 47.4570 \\
Landsat8 OLI/TIRS & $2014-9-19$ & LC81160272014262LGN00 & 130.0368 & 47.4492 \\
\hline
\end{tabular}

high-dimensional data, small sample sizes, nonlinearity, and so on, and has high accuracy and stability for the classification of objects [10]. An SVM based on supervised classification separates multi-spectral feature data into discrete predefined clusters consistent with the training dataset in the remote sensing image classification application, so that the classification accuracy and stability are higher and the error is relatively small.

Let the training area for the study area be $\left\{x_{i}, y_{i}\right\}_{i=1}^{N}$, where $x_{i} \in R^{n}$ represents the input mode and $y_{i} \in\{-1,1\}$ represents the target output. Set the optimal decisionmaking equation: $\omega^{T} x_{i}+b=0$, then the weight vector $\omega$ and bias $b$ to meet the constraints:

$$
y_{i}\left(\omega^{T} x_{i}+b\right) \geq 1-\xi,
$$

Where $\xi$ is a slack variable under the condition of indivisible linearity, which indicates the degree of deviation of the pattern in the ideal linear case. From the classification of training samples required to minimize the error, we can deduce the following optimization formula:

$$
\Phi(\omega, \xi)=\frac{1}{2} \omega^{T} \omega+C \sum_{i=1}^{N} \xi,
$$

where $C$ is the penalty coefficient, which indicates that the SVM penalizes the misclassified samples and reflects the 
balance between the misclassification ratio and the complexity of the algorithm [31]. Using the Lagrange multiplier method, the optimal decision surface can be transformed into the following optimization constraints:

$$
Q(a)=\sum_{i=1}^{N} a_{i}-\frac{1}{2} \sum_{i=1}^{N} \sum_{j=1}^{N} a_{i} a_{j} y_{i} y_{j} K\left(x_{i}, y_{j}\right),
$$

where $A$ is the Lagrange multiplier, but also to meet the constraints:

$$
\sum_{i=1}^{N} a_{i} y_{i}=0,0 \leq a_{i} \leq C, i=1,2,3, \ldots, N,
$$

$\mathrm{K}\left(\mathrm{x}, \mathrm{x}_{i}\right)$ is a kernel function that satisfies the Mercer theorem. The kernel function has many forms, including linear, radial basis function (RBF), and polynomial, and by setting different kernel functions and parameters, its classification effect is different.

According to field research results, texture characteristics and spectral information combined with visual interpretation of Hegang coal mining land use types, using the SVM classification method, the landscape types of the study area are divided into eight categories, which include grassland, arable land, woodland, waters, residential land, coal land, unused land, and transport land.

The evaluation unit is a series of factors that affect the quality of the environment, which can reflect the difference of a certain quality of the environment. The commonly used evaluation units at home and abroad are planar-based vector units or point-based grid units. In this study, landscape-based vector surface units were used as evaluation carriers, and 63,047 patches were used as evaluation units to perform land use exposure, sensitivity, and adaptability evaluation and analysis of the comprehensive vulnerability of land from 1994 to 2014. Finally, the land use vulnerability in the study area is divided into five levels and the vulnerability of spatialization.

\subsubsection{AHP to determine the weight of the vulnerability assessment index}

AHP is a decision-aiding method developed by Saaty [32]. The strength of AHP is that it organizes tangible and intangible factors in a systematic way, and provides a structured, yet relatively simple, solution to decision-making problems [33]. The AHP system analysis should be based on a certain amount of information and people make judgments about the relative importance of each unit in each level. These judgments are expressed numerically by the introduction of a suitable scale, written as a judgment of the matrix:

$$
A=\left[\begin{array}{cccc}
1 & a_{12} & \cdots & a_{1 n} \\
a_{21} & 1 & \cdots & a_{2 n} \\
\cdots & \cdots & \cdots & \cdots \\
a_{n 1} & a_{n 2} & \cdots & a_{n n}
\end{array}\right],
$$

where $A$ is the discriminant matrix. For $a_{m n}$, element $m$ and element $n$ represent the importance comparison results (Table 2).

Table 2: Proportional scale of importance assignment.

\begin{tabular}{cc}
\hline $\begin{array}{c}\text { Evaluation } \\
\text { value }\end{array}$ & Influence level \\
\hline$a_{m n}=1$ & $A_{m}$ has the same effect as $A_{n}$ \\
$a_{m n}=3$ & $A_{m}$ slightly stronger than $A_{n}$ \\
$a_{m n}=5$ & $A_{m}$ has stronger influence than $A_{n}$ \\
$a_{m n}=7$ & $A_{m}$ significantly stronger than $A_{n}$ \\
$a_{m n}=9$ & $A_{m}$ is absolutely stronger than $A_{n}$ \\
$a_{m n}=2,4,6,8$ & Indicates the middle value of the adjacent \\
& judgment \\
\hline
\end{tabular}

Having made all the pair-wise comparisons, the consistency is determined by using the eigenvalue, $\lambda_{\max }$, to calculate the consistency index, $C I$.

$$
C I=\left(\lambda_{\max }-n\right) /(n-1)
$$

where $n$ is the matrix size. When $C I<0.1$, the representative comparison matrix satisfies the consistency requirement and the assignment data is valid.

Luers [34] believed that ecosystems and the environment were affected to varying extents and frequencies by varying degrees of vulnerability, which were defined as exposures. Turner [35] used the HR and PAR models to explain the exposure and concluded that stress on the environment is a major exposure function. The sensitivity of land use under the system of human-earth coupling is manifested as the disastrous power of the disturbed regional ecosystem, which is positively correlated with the vulnerability. In the context of studies on global change and eco-environmental vulnerability, adaptive capacity is defined as the ability to adapt to, or reduce, systemic vulnerability [36] and is an ability to reduce the extent of vulnerability. Therefore, the combination of qualitative and quantitative methods, multi-dimensional analysis of the study area of land use vulnerability formation mechanisms, and characteristics, firstly, establish the target layer, criterion layer, element layer, and index layer from three aspects of the ecosystem's exposure, sensitivity, 


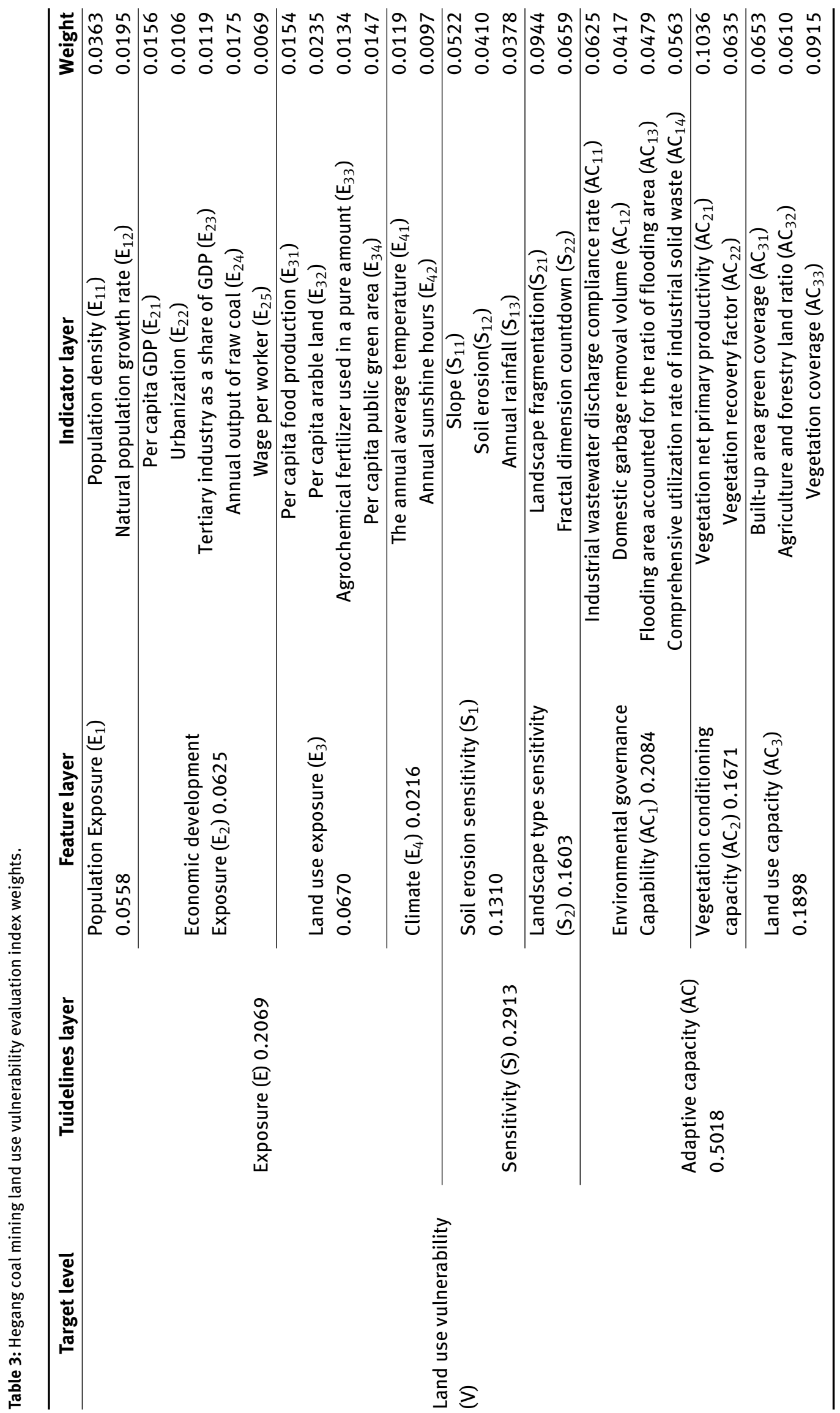


and adaptability, and establish an accurate and complete evaluation system, and then use AHP and expert consultation to establish the weight (Table 3).

\subsubsection{The evaluation factor of normalization}

Before data analysis, we usually need to normalize the data first, and map the data to the range of $0-1$, which makes the calculation easy and fast [37] Vulnerability is positively correlated with the inverse index and negatively correlated with the positive index.

The images of 1994, 2006, 2010, and 2014 obtained the slop, soil erosion, vegetation coverage, net primary productivity of vegetation, landscape fragmentation, and reciprocal fractal dimension data. Other data were obtained from the four-year statistical yearbook combined with field research data and other supporting data (Table 4).

Table 4: The 1994-2004 research area vulnerability assessment indicator original values.

\begin{tabular}{|c|c|c|c|c|c|}
\hline Index & $\stackrel{\bar{\varpi}}{\searrow}$ & 1994 & 2006 & 2010 & 2014 \\
\hline$\overline{E_{11}}$ & & 150 & 150.41 & 149.13 & 152.04 \\
\hline $\mathrm{E}_{12}$ & & 7.95 & 1.04 & -0.96 & -1.36 \\
\hline$E_{21}$ & & 2579 & 11862 & 23044 & 24245 \\
\hline$E_{22}$ & & 72.84 & 80.61 & 80.9 & 80.91 \\
\hline$E_{23}$ & & 30.6 & 34.69 & 29.13 & 24.23 \\
\hline$E_{24}$ & & 1150.2 & 1865.2 & 1801.398 & 1309.5 \\
\hline $\mathrm{E}_{25}$ & & 2852.05 & 18479.6 & 25247.5 & 38713 \\
\hline$E_{31}$ & & 0.2042 & 0.5663 & 0.7182 & 0.8979 \\
\hline$E_{32}$ & & 1.587 & 6.49 & 6.08 & 3.07 \\
\hline$E_{33}$ & & 10703 & 21032 & 36128 & 42100 \\
\hline$E_{34}$ & & 11.4 & 11.9 & 14.9 & 15.3 \\
\hline$E_{41}$ & & 3.7 & 3.6 & 3.3 & 3.1 \\
\hline$E_{42}$ & & 2534.5 & 2501 & 2354.5 & 2521.3 \\
\hline $\mathrm{S}_{13}$ & & 967.6 & 605.9 & 863.5 & 865.4 \\
\hline $\mathrm{AC}_{11}$ & & 40 & 83.13 & 94.6 & 100 \\
\hline $\mathrm{AC}_{12}$ & & 39 & 95 & 70.6 & 32.6 \\
\hline $\mathrm{AC}_{13}$ & & 59 & 77.1 & 80.7 & 82.3 \\
\hline $\mathrm{AC}_{14}$ & & 58.87 & 78.06 & 83.7 & 89 \\
\hline $\mathrm{AC}_{22}$ & & 78 & 86 & 89 & 92 \\
\hline $\mathrm{AC}_{31}$ & & 23.2 & 38.4 & 39.23 & 47.22 \\
\hline $\mathrm{AC}_{32}$ & & $78.39 \%$ & $77.82 \%$ & $78.29 \%$ & $64.66 \%$ \\
\hline $\mathrm{AC}_{14}$ & & 3.7 & 3.6 & 3.3 & 3.1 \\
\hline $\mathrm{AC}_{22}$ & & 2534.5 & 2501 & 2354.5 & 2521.3 \\
\hline $\mathrm{AC}_{31}$ & & 967.6 & 605.9 & 863.5 & 865.4 \\
\hline $\mathrm{AC}_{32}$ & & 40 & 83.13 & 94.6 & 100 \\
\hline
\end{tabular}

\subsubsection{GIS spatial analysis and vulnerability evaluation model}

Spatial analysis is a spatial data analysis technique about the characteristics of geographical forms and the location of their objects. It can obtain important information, such as spatial location, shape, distribution, and evolution related to geographical objects from numerous spatial data [38]. GIS can achieve the basic functions of spatial analysis, including spatial query and measurement, buffer analysis, overlay analysis, path analysis, spatial interpolation, and statistical classification analysis. In this study, the mathematical model was integrated with GIS spatial analysis to analyze the vulnerability of land use.

\section{(1) Vulnerability evaluation model}

According to the concept models and equations proposed by Metzger [39] and Turner [35], the landscape ecological principles and system theory are used to synthesize the indicators of multiple sub-system parameters. According to the vulnerability of the human-land coupling system in the study area, exposure, sensitivity, and adaptive capacity of the Hegang coal mine land use the vulnerability of three models:

$$
\begin{aligned}
V & =(E+S) / A C \\
& =\left(\sum_{i}^{n} W_{i} X_{s i}+\sum_{j}^{m} W_{j} X_{e j}\right) \sum_{k=1}^{p} W_{k} X_{a c k}, \\
E & =f\left(X_{1}, X_{2} \ldots \ldots X_{m}\right)=\sum_{j=1}^{m} W_{j} X_{e j} \\
S & =f\left(X_{1}, X_{2} \ldots \ldots X_{n}\right)=\sum_{i=1}^{n} W_{i} X_{s i} \\
A C & =f\left(X_{1}, X_{2} \ldots \ldots X_{p}\right)=\sum_{k=1}^{p} W_{k} X_{a c k}
\end{aligned}
$$

In the formula:

$V$ is the land use vulnerability;

$E$ is the environmental exposure of land use;

$S$ is the environmental sensitivity of land use;

$A C$ is the environment adaptive capacity;

$n, m, p$ are the number of participating factors of sensitivity, exposure, and adaptive capacity; and $W_{i}, W_{j}, W_{k}$ are the weights of the factors of sensitivity, exposure, andadaptive capacity.

When $V>1$, it indicates that the potential impact outside the environment is greater than the adaptive capacity, the vulnerability highlights, and the ecological envi- 
Table 5: Classification of different land use types in the study area.

\begin{tabular}{cccccc}
\hline Grade & I & II & III & IV & V \\
\hline Regionalization & Potentially & Mildly vulnerable & Moderately & Severely & Extremely fragile \\
& vulnerable area & area & vulnerable area & vulnerable area & area \\
EVI & $0-5.0$ & $5.0-10.0$ & $10.0-20.0$ & $20.0-30.0$ & $30.0-50.0$ \\
\hline
\end{tabular}

ronment have deteriorating trends. When $V<1$, the vulnerability of the environment is invisible and is in a trend of recoverability.

\section{(2) Vulnerability index calculation model and vulnerability classification}

The ecological vulnerability is a comprehensive manifestation of the vulnerability under the structure and function of the landscape type. The regional environmental vulnerability index can reflect the ecological vulnerability of the whole region. The calculation formula of the vulnerability index (RVI) is as follows [40]:

$$
R V I_{j}=\sum_{i=1}^{n} \frac{A_{i}}{A} V,
$$

$A_{i}$ is the area of the $i$ th landscape type in the area; $A$ is the total size of the area.

According to the research on the existing results of vulnerability classification [41] the vulnerability values are divided into five grades according to the actual situation of land use vulnerability in the study area, and the vulnerability values are classified into regions with different degrees of vulnerability according to the grades (Table 5).

\section{Results and discussion}

\subsection{The Normalization of the Coal Mine Evaluation Index}

Different indicators affect the ecological environment in different ways. After the assessment of the positive and negative relations, the normalized equation is used to normalize the evaluation indices of vulnerability of the Hegang coal mine area and finally obtain a value (Table 6). The larger the normalized index value, the greater the effect of the indicator factor on environmental vulnerability.
Table 6: Normalized values of indicators of vulnerability assessment data from 1994 to 2014 in the study area.

\begin{tabular}{lccccc}
\hline Index & \multirow{\Xi}{*}{} & 1994 & 2006 & 2010 & 2014 \\
\hline $\mathrm{E}_{11}$ & & 0.1988 & 0.1993 & 0.1976 & 0.2015 \\
$\mathrm{E}_{12}$ & & 0.4701 & 0.0615 & 0.0568 & 0.0804 \\
$\mathrm{E}_{21}$ & & 0.0379 & 0.1744 & 0.3389 & 0.3565 \\
$\mathrm{E}_{22}$ & & 0.1890 & 0.2091 & 0.2099 & 0.2099 \\
$\mathrm{E}_{23}$ & 0.2010 & 0.2278 & 0.1914 & 0.1591 \\
$\mathrm{E}_{24}$ & 0.1557 & 0.2525 & 0.2439 & 0.1773 \\
$\mathrm{E}_{25}$ & 0.0309 & 0.2005 & 0.2738 & 0.4199 \\
$\mathrm{E}_{31}$ & 0.0729 & 0.2022 & 0.2564 & 0.3206 \\
$\mathrm{E}_{32}$ & 0.0706 & 0.2887 & 0.2705 & 0.1366 \\
$\mathrm{E}_{33}$ & 0.0863 & 0.1697 & 0.2915 & 0.3396 \\
$\mathrm{E}_{34}$ & 0.1762 & 0.1839 & 0.2303 & 0.2365 \\
$\mathrm{E}_{41}$ & 0.2114 & 0.2057 & 0.1886 & 0.1771 \\
$\mathrm{E}_{42}$ & 0.2052 & 0.2024 & 0.1905 & 0.2040 \\
$\mathrm{~S}_{13}$ & 0.2586 & 0.1619 & 0.2307 & 0.2312 \\
$\mathrm{AC}_{11}$ & 0.1259 & 0.2616 & 0.2978 & 0.3147 \\
$\mathrm{AC}_{12}$ & 0.1198 & 0.2918 & 0.2168 & 0.1001 \\
$\mathrm{AC}_{13}$ & 0.1572 & 0.2055 & 0.2152 & 0.2193 \\
$\mathrm{AC}_{14}$ & 0.1567 & 0.2078 & 0.2229 & 0.2370 \\
$\mathrm{AC}_{22}$ & 0.1827 & 0.2014 & 0.2084 & 0.2155 \\
$\mathrm{AC}_{31}$ & 0.1341 & 0.2219 & 0.2267 & 0.2728 \\
$\mathrm{AC}_{32}$ & 0.2073 & 0.2058 & 0.2071 & 0.1710 \\
$\mathrm{AC}_{14}$ & 0.1567 & 0.2078 & 0.2229 & 0.2370 \\
$\mathrm{AC}_{22}$ & 0.1827 & 0.2014 & 0.2084 & 0.2155 \\
$\mathrm{AC}_{31}$ & 0.1341 & 0.2219 & 0.2267 & 0.2728 \\
$\mathrm{AC}_{32}$ & 0.2073 & 0.2058 & 0.2071 & 0.1710 \\
\hline & & & &
\end{tabular}

\subsection{Land Use Exposure Evaluation and Analysis}

This paper evaluates the land use exposure of Hegang coal mine from four aspects of population exposure, economic development exposure, land development exposure, and climate. The greater the exposure value, indicating that the greater the degree of interference, a value greater than 0 indicates that the exposure was dominant, increased vulnerability. According to the weight of each index of land use, and the normalized value of the index in the study area, the exposure index of different landscape types from 
1994 to 2014 was calculated by Equation (7) and Equation (8) (Figure 2).

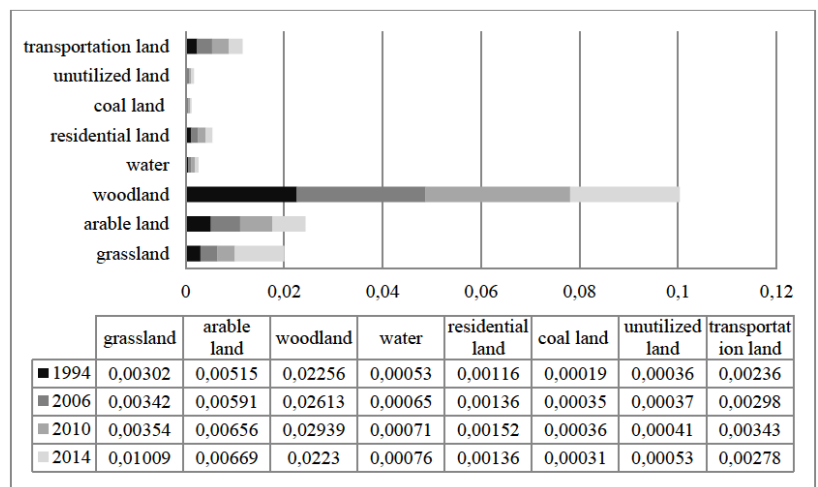

Figure 2: Calculation results of land use exposure index in the study area from 1994 to 2014.

The overall results of the landscape type exposures from 1994 to 2014 show that the overall exposure of the study area shows an increasing trend. According to the exposure of four different landscape types, although the exposure index value of woodland in 2014 is less than the exposure value in 1994, the overall exposure index is greater than other landscape types; grassland, arable land, water area, residential land, land for coal mines, unutilized land, and transportation land increased between 1994 and 2014, and all showed signs of increasing exposure to varying degrees. It can be seen from 1994 to 2014 that the ecological environment of land use in the study area is affected by the exposure and the influence degree shows a gradual increasing trend.

\subsection{Land Use Sensitivity Evaluation and Analysis}

Land use sensitivity is the main indicator of vulnerability performance. The greater the degree of sensitivity, the greater the possibility that the environment will be disturbed by human interference activities or by natural factors themselves, and the more obvious the vulnerability. By analyzing the sensitivity of land use, we can determine the main ecological problems and the degree of possible occurrence in the study area, thus providing effective measures and guidance for the suppression of potential vulnerabilities.

It can be seen from Figure 3 that the sensitivity of land use in Hegang from 1994 to 2014 shows a slight downward trend. According to the 20-year trend of sensitivity of vari- ous types of land use, sensitivity of grassland, arable land, water, residential land, coal land, and transportation land has been aggravated. Woodland and unutilized land show a decreasing trend; in 1994, the sensitivity index of landscape type showed that the woodland land and the unutilized land had higher sensitivity and obvious interference ability. In 2006 and 2010, the coal land, woodland, and unutilized land are still more sensitive. In 2014, the land for transportation started to be exacerbated by natural and man-made interference, showing a tendency of increasing sensitivity.

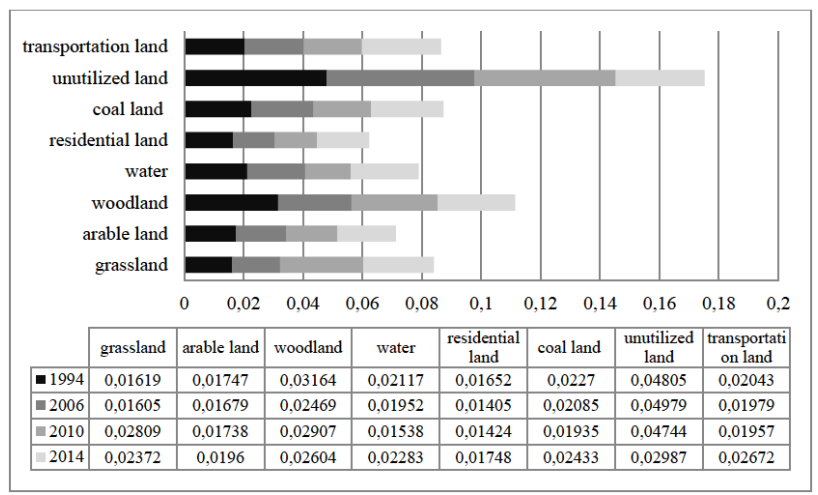

Figure 3: Calculation results of land use sensitivity index in the study area from 1994 to 2014.

\subsection{Land Use Adaptive Capacity Evaluation and Analysis}

With the prominent exposure of land use and its sensitivity in the Hegang coal mine, it is expected that some economic or social measures will be taken in the region to improve their adaptive capacity. The adaptive capacity is controllable and subjective. Nine evaluation indices were selected from three aspects of the environmental management ability, vegetation regulation capacity, and land utilization ability in the study area to establish a system to evaluate the adaptive capacity of land use, and the result is shown in Figure 4.

From the calculation results of the index of land use adaptive capacity in the study area from 1994 to 2014, we can see that the overall adaptive capacity has an upward trend, which is closely related to the governance and protection policies adopted in the region. According to the law of development of adaptive capacity of various landscape types, it can be found that, in addition to the decrease of adaptive capacity of forest land, the adaptive capacity of 


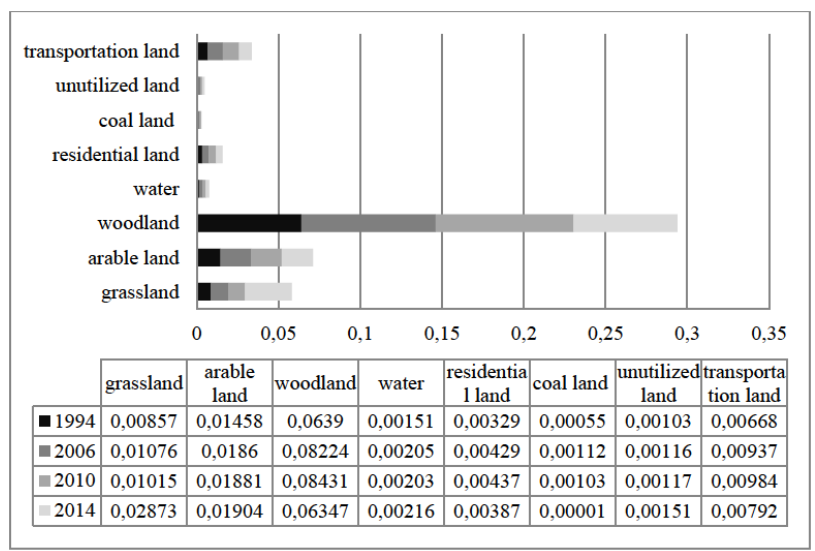

Figure 4: Calculation results of the land use adaptive capacity index in the study area from 1994 to 2014.

other land uses tends to increase. Judging from the adaptive capacity of land use types in various periods, grassland, cultivated land, and woodland showed high adaptive capacity from 1994 to 2014, indicating that its stability is strong. The coal mine land shows the weakest adaptive capacity to adapt to the less resilient external environment.

\subsection{Comprehensive Evaluation of Land Use Vulnerability and Analysis of Spatial Differentiation}

\subsubsection{Integrated quantitative analysis of land use vulnerability}

The Hegang coal mine has its own special complicated urban system and the vulnerability of human-ground coupling is obvious. Under the common interference of human factors and natural factors, the vulnerability of the ecological environment in the study area has become increasingly evident. Based on the economic system, social system, and eco-environment system, this paper constructs a vulnerability assessment system and mathematical calculation model of the Hegang coal mine area from the aspects of exposure, sensitivity, and adaptive capacity, the study area exposure index, sensitivity index, and adaptive capacity index calculation. The use of ARCGIS software overlays the analysis of the results and spatial statistics, with the results shown in Figure 5.

The order of overall fragility of landscape types in the Hegang coal mine area from 1994 to 2014 is: unused land $>$ coal land $>$ waters $>$ residential land $>$ transport land $>$ grassland $>$ arable land $>$ woodland, among them, the

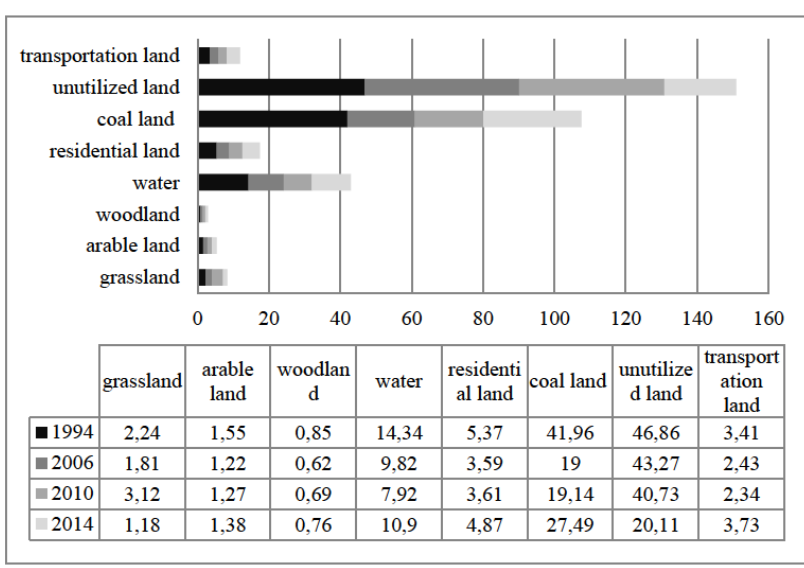

Figure 5: Calculation results of comprehensive vulnerability of the land use in the Hegang coal mining area.

value of vulnerability of woodland is less than 1 , others are all more than 1, this shows that under the coupling of humans and land, the overall ecological environment of the study area has less self-adaptation and adjustment capacity than the combined effect of external exposure and sensitivity, and the ecological environment is in a worsening situation. Although the vulnerability index of woodland shows an increasing trend to 1 , and although the adaptive capacity is slightly larger than the overall capability of exposure and sensitivity, it has little effect on the environmental regulation in the whole area. The vulnerability of land use in coal mining areas is obviously prominent, the ecological vulnerability is serious, and the ecological environment is deteriorating.

\subsubsection{Spatial differentiation analysis of land use vulnerability in coal mining areas}

According to the integrated value of land use vulnerability in the study area, the fragmented area is divided according to the fragile value area, and the vulnerability grade distribution map is generated after spatialization (Figure 6).

As can be seen from Figure 6, from the perspective of the spatial distribution of vulnerability, the coal mine in Hegang from 1994 to 2014 was mostly in the fragile zone because of the vast majority of forest land in the northern and central regions with relatively high adaptive capacity. The basic trend of vulnerability in the central urban area ranged from mild vulnerability in 1996 to a region of extreme vulnerability in 2001, and it was a severe vulnerability in 2014. This result is consistent with the overall vulnerability assessment data. 


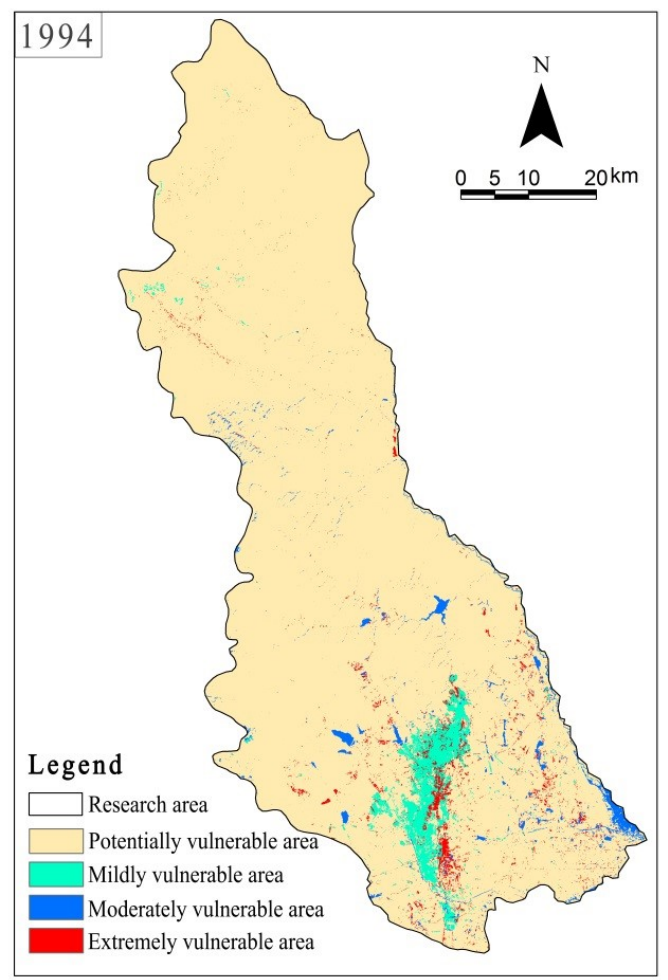

(a)

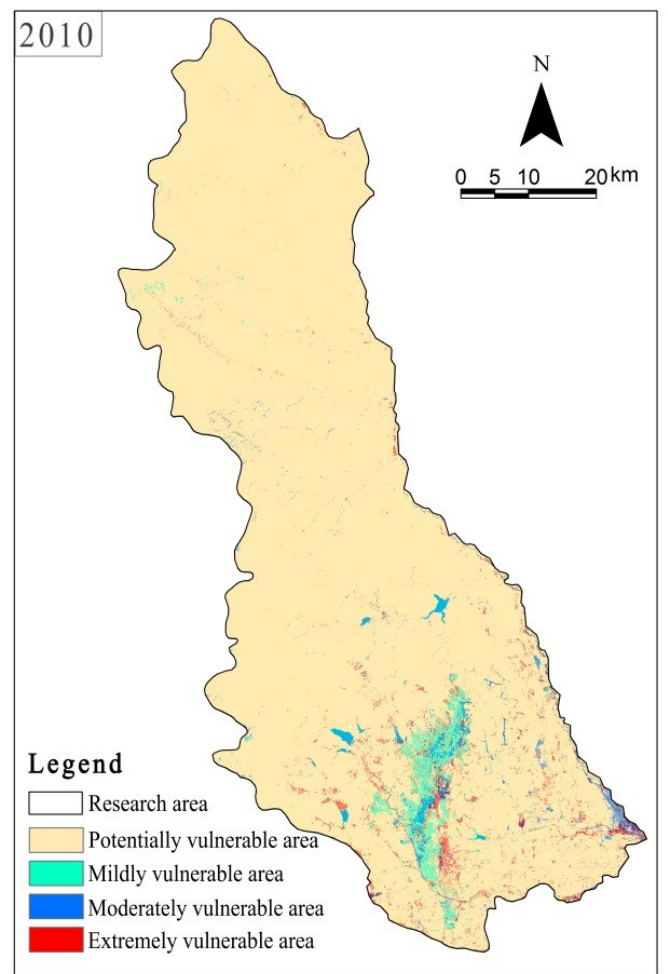

(c)

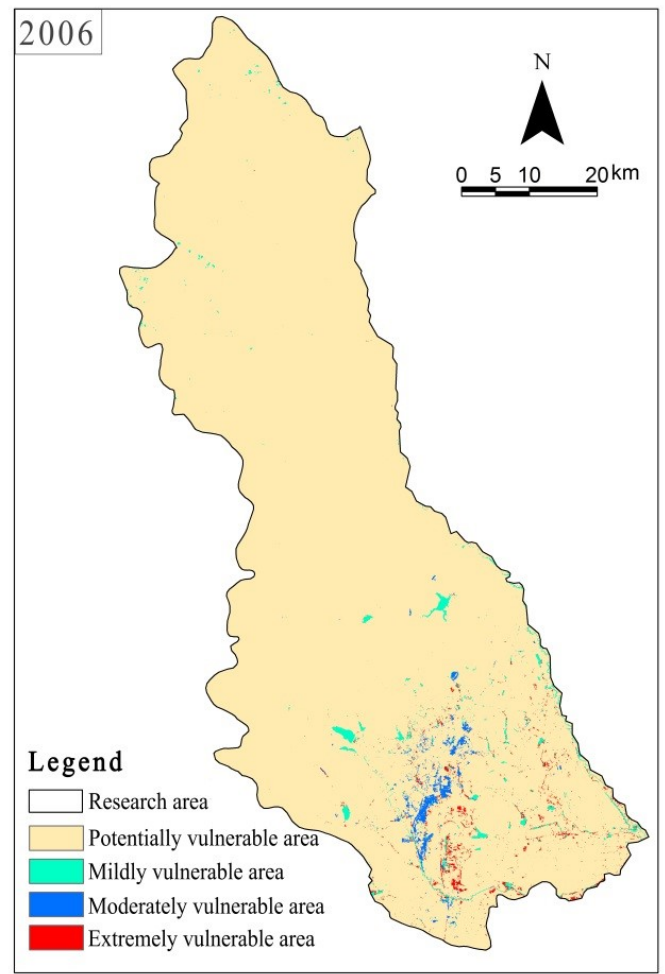

(b)

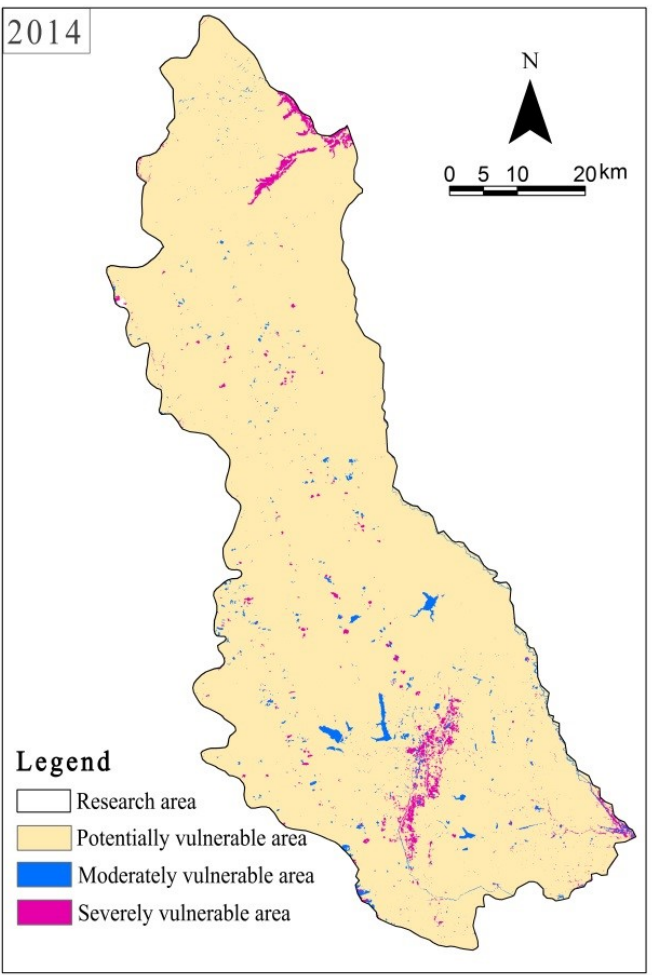

(d)

Figure 6: Spatial distribution of land use vulnerability in the study area of Hegang from 1994-2014. 
In terms of the change of time, compared with 1994, the area of mildly vulnerable areas decreased, the moderately vulnerable areas gradually concentrated, the extremely vulnerable areas expanded, and the overall vulnerability obviously moved toward the dominant trend. Compared with 2006, the extremely vulnerable areas spread to the periphery in 2010, but their area has been reduced. In 2014, compared with 2010, the extremely vulnerable areas in 2010 weakened and their vulnerability to moderately vulnerable areas increased. Most of them were converted into highly vulnerable areas and the mildly vulnerable areas were transformed into moderately vulnerable areas. On the whole, although the index of vulnerability decreased gradually from 1994 to 2014, it was still far greater than 1, and the vulnerability was obviously highlighted. The serious areas of vulnerability were mainly distributed in the southern urban area with a strong human disturbance.

From the perspective of urban sustainable development, there are some contradictions between the environment and the economy. How to increase the economy while ensuring the environment is not damaged is something that we should study. Due to the complexity of the causes of vulnerability, each type of land-use sensitivity, exposure, and ability to resist natural or man-made interference need to be adapted to meet the needs of sustainable development. Therefore, it is necessary to quickly find out ways to mitigate and control the increasing vulnerability of different landscape types, and it is also a direction that needs to be studied for a long time.

As a special city group, there has been little research on the coal mine city, especially the land use vulnerability in the coal mine area. With the deterioration of the internal structure and bearing capacity of the land use landscape, human disturbance gradually shows the phenomenon of vulnerability. In order to solve the problems caused by the increasing environmental damage, the related research of coal cities should be strengthened and corresponding ecological remedies should be taken. Therefore, in future research, more efforts should be made with respect to the coal mine city to deeply explore and reveal the interference effect of the coupling relation between humankind and the natural environment.

Hegang coal mine land use shows the most prominent vulnerability, with the surrounding environment and natural factors being greatly affected by human factors. Therefore, ecological restoration should be taken as a priority strategy to utilize the means of vegetation restoration, soil quality improvement, and natural landscape maintenance in the process of natural evolution to give priority to improving the adaptability of natural ecosystems.
Different landscape types have different security patterns and play a decisive role in their stability. They can effectively protect the landscape security pattern in order to maintain a healthy ecological landscape and the ecological environment in areas with fragile landscape restoration.

\section{Conclusions}

In this study, based on the coupled human-environment, using RS and GIS technology, through the SVM classification method divides the research into eight categories, the construction of an evaluation index system and AHP to determine the weight of evaluation units, the standardization of evaluation index data, and the construction of evaluation model and vulnerability index calculation model, the vulnerability of different landscape types in the coal mining area from 1994 to 2014 was evaluated from the time and space dimensions, and the following conclusions were reached:

First, from the time change point of view, the ecological adaptive capacity of the Hegang coal mine area is less than the combined effect of exposure and sensitivity during 1994-2014, the degree of vulnerability is obviously highlighted, the phenomenon of vulnerability is aggravated, and the ecological environment is deteriorating. Second, from the perspective of spatial heterogeneity, the vulnerability in the northern and central parts of the study area are relatively weak, while the vulnerability in the southern part is obvious, and is concentrated in moderate, severe, and extremely vulnerable areas. The overall distribution of vulnerable regions of ecosystems shows a tendency of spreading from south to north, changing from mildly vulnerable to moderately vulnerable and from moderately vulnerable to more severely vulnerable. Finally, from the perspective of vulnerability of landscape types, coal mines and unutilized land are the most disturbed by humans and nature, showing strong vulnerability. Due to their relatively large area and relatively high adaptive capacity, woodland shows potential vulnerability, however, on the whole, the landscape types have the tendency to aggravate the vulnerability of woodland.

As a special city group, there has been little research on the coal mine city, especially the land use vulnerability in the coal mine area. The study about the vulnerability of land use in coal mining areas, which not only provides case references for the study of vulnerability of small cities in special cities, but also guides the direction of ecological restoration, which is of great significance.With the 
deterioration of the internal structure and bearing capacity of the land use landscape, human disturbance gradually shows the phenomenon of vulnerability. In order to solve the problems caused by the increasing environmental damage, the related research of coal cities should be strengthened and corresponding ecological remedies should be taken. Therefore, in future research, more efforts should be made with respect to the coal mine city to deeply explore and reveal the interference effect of the coupling relation between humankind and the natural environment.

At present, the results of this study have been approved by the protection department of Hegang Coal Mine Area, and relevant recommendations have been adopted to protect and ecologically rehabilitate severely vulnerable areas and develop towards a good trend.Due to the complexity of factors and data limitations, the scientific evaluation index system still needs to be improved. How to carry out the coordinated development of regional environment under the coupled human-environment, to achieve a virtuous circle of people's ecological environment, still requires in-depth study.

Acknowledgement: The authors would like to express gratitude to the research grant support kindly provided by China Postdoctoral Science Foundation (Grant No.2017M621229), Postdoctoral Science Foundation of Heilongjiang Province(Grant No.LBH-Z17001), the National Natural Science Foundation of China for Young Scholars (Grant No.41101177), Philosophy and social science program in Heilongjiang Province(Grant No.17GLD173, Grant No. 16GLC04), Scientific Research Foundation for the Returned Overseas Chinese Scholars, Heilongjiang Province, the University Strategic Reserve Personnel Abroad Research project funded by Heilongjiang Province, University Nursing Program for Young Scholars with Creative Talents in Heilongjiang Province.

\section{References}

[1] Bierbaum R., Smith J.B., Lee A., Blair M., Chapin F.S. A comprehensive review of climate adaptation in the United States: more than before, but less than needed. Mitig. Adapt. Strat. Gl., 2013, 18, 361-406.

[2] IPCC(Intergovernmental Panel on Climate Change). Climate change 2014: synthesis report. contribution of working groups I, II and III to the fifth assessment report of the intergovernmental panel on climate change [Core Writing Team, R.K. Pachauri and L.A. Meyer (eds.)]. Geneva Switzerland, 2014, 151.

[3] Abson D.J., Dougill A.J., Stringer L.C. Using principal component analysis for information-rich socio-ecological vulnerability mapping in Southern African. Appl.Geogr.,2012, 35, 515-524.

[4] Coletti A., Howe P.D., Yarnal B. A support system for assessing local vulnerability to weather and climate. Nat. Hazards.,2013, 65, 999-1008.

[5] Ippolito A., Sala S., Faber J.H. Ecological vulnerability analysis: a river basin case study. Sci. Total. Environ., 2010, 408, 3880 3890.

[6] Roberta A., Teodoro S., Irene P.,Antonella D.M., Maria R.P., Giovanni Z. Mapping ecological vulnerability to fire for effective conservation management of natural protected areas. Ecol. Model., 2015, 295, 163-175.

[7] Sen G., Bayramoglu M.M., Toksoy D. Spatiotemporal changes of land use patterns in high mountain areas of Northeast Turkey: a case study in Macka. Environ. Monit. Assess. 2015,187, 515.

[8] Lee Y.J. Social vulnerability indicators as a sustainable planning tool. Environ. Impact. Assess.,2014, 44, 31-42.

[9] Mudrák O., Frouz J., Velichová V. Understory vegetation in reclaimed and unreclaimed post-mining forest stands. Ecol. Eng., 2010, 36, 783-790.

[10] Zégre N.P., Maxwell A., Lamont S. Characterizing streamflow response of a mountain top-mined watershed to changing land use. Appl.Geogr., 2013, 39, 5-15.

[11] Karan S.K., Samadder S.R. Reduction of spatial distribution of risk factors for transportation of contaminants released by coal mining activities. J. Environ. Manage.,2016, 180, 280.

[12] Grothmann T., Petzold M., Ndaki P., Kakembo V., Siebenhuner B., Kleyer M., Yanda P., Ndou N. Vulnerability assessment in African villages under conditions of land use and climate change: case studies from Mkomazi and Keiskamma. Sustainability., 2017, 9, 976.

[13] Li J.Y., Zheng X.Q., Zhang C.X., Chen Y.M. Impact of land-use and land-cover change on meteorology in the Beijing-Tianjin-Hebei region from 1990 to 2010. Sustainability., 2018, 10, 176.

[14] Ribeiro P., Albuquerque A., Quinta-Nova L.,Cavaleiro V. Recycling pulp mill sludge to improve soil fertility using GIS tools. Resour. Conserv. Recy., 2010, 54, 1303-1311.

[15] Demirel N., Emil M.K., Duzgun H.S. Surface coal mining area monitoring using multi-temporal high resolution satellite image. Int. J. Coal. Geol., 2011, 86, 3-11.

[16] Lioubimtseva E. A multi-scale assessment of human vulnerability to climate change in the Aral Sea basin. Environ. Earth Science., 2015, 73, 719-729.

[17] Rajarathnam S., Santhakumar A.R. Assessment of seismic building vulnerability based on rapid visual screening technique aided by aerial photographs on a GIS platform. Nat. Hazards., 2015, 78, 779-802.

[18] Liao X.Q., Li W., Hou J.X. Application of ecological vulnerability evaluation in plan environmental impact assessment of mining areas: a case study of Fuxin mining area. J. Environ. Sci-China., 2013, 33, 1891-1896.

[19] Ryoji Y., Kumiko T., Jun M. Numerical study of the impacts of land use/cover changes between 1700 and 1850 on the seasonal hydroclimate in monsoon Asia. J.Meteorol. Soc. JPN.,2011,89A, 291-298.

[20] Pathirana A., Denekew H.B., Veerbeek W.,Zeven-bergen C., Banda A.T. Impact of urban growth-driven land use change on micro climate and extreme precipitation-A sensitivity study. Atmos. Res., 2014, 138, 59-72.

[21] Soffianian A., Madanian M. Monitoring land cover changes in Isfahan Province, Iran using Landsat satellite data. Envi- 
ron.Monit. Assess.,2015,187, 543.

[22] Vitousek P.M., Mooney H.A., Lubchenco J., Melillo J.M. Human domination of earth's ecosystems. Science.,2008, 277, 494499.

[23] Webster I.T., Harris G.P. Anthropogenic impacts on the ecosystems of coastal lagoons: Modelling fundamental biogeochemical processes and management implications. Mar. Freshwater. Res.,2004,55, 67-78.

[24] Güneralp B., Güneralp N., Castillo C.R.,Filippi A.M. Land change in the Mission-Aransas coastal region, texas: implications for coastal vulnerability and protected areas. Sustainability., 2013, 5, 4247-4267.

[25] Jiang Y.X., Dexian LI., Gao Y. Analysis of leaching and release of heavy metals in soil and tailings of Dabaoshan mining area in northern Guangdong. Chinese Journal of Ecology., 2013,32, 1038-1044.

[26] Chen X., CHU Y., LI J. Assessment of mine ecological environment in Hegang coal mine area based on RS and AHP. Forest. Engineering., 2012, 28, 26-30.

[27] Roberts M.G., Yang G.A. The international progress of sustainable development research: a comparison of vulnerability analysis and the sustainable livelihoods approach. Prog. Phys. Geog., 2003, 22, 11-21.

[28] Chambers R. Vulnerability, coping and policy (editorial introduction). Ids. Bulletin., 2006, 37, 33-40.

[29] Turner II B.L., Matson J.J., Mccarthy R.W. Illustrating the coupled human-environment for vulnerability analysis: three case studies. P. Natl. Acad. Sci. USA., 2003, 100, 8080-8085.

[30] Mountrakis G., Im J., Ogole C. Support vector machines in remote sensing: a review. ISPRS. J.Photogramm., 2011,66, 247 259.

[31] Zhang J.Q., Wang W.J. The research of Remote Sensing image fine classification based on cross validation. Urban Geotechnical Investigation \& Surveying., 2016, 2, 88-96.
[32] Saaty T.L. How to make a decision: the analytic hierarchy process. Eur. J.Oper. Res.,1990,48, 9-26.

[33] Skibniewski M.J., Chao L. Evaluation of advanced construction technology with AHP method. J. Constr. Eng. M. ASCE.,1992, 118, 577-593.

[34] Luers A.L., Lobell D.B., Sklar L.S., Addams C.L., Matson P.A. A method for quantifying vulnerability, applied to the agricultural system of the Yaqui Valley. Global. Environ. Change., 2003, 13, 255-267.

[35] Turner B.L., Kasperson R.E., Matson P.A. A framework for vulnerability analysis in sustainability science. Proc. Natl. Acad. Sci. USA.,2003, 100, 8074-8079.

[36] Luers A.L. The surface of vulnerability: an analytical framework for examining environmental change. Globel Environment Change, 2005, 15, 214-223.

[37] Guo R.Z. Spatial analysis (Second Edition). Higher Education Press, Beijing, China, 2011.

[38] Fen F.L., Yan L., Guo Z.H. Evaluation of the changes of ecoenvironmental vulnerability in Quanzhou bay estuary wetlands in 1989 and 2008. Chinese Journal of Applied Oceanography, 2013, 32, 577-582.

[39] Metzger M.J., Rounsevell M., Acosta L. The vulnerability of ecosystem services to land use change. Agr.Ecosyst. Environ., 2006, 114, 69-85.

[40] Huang Y., Bao A.M., Liu H.L. Comprehensive evaluation of ecological vulnerability in Xinjiang based on landscape pattern. Agrarian Regional Agriculture Research, 2009, 27, 261-266.

[41] Cizelj L., Leskovar M., Čepin M., Mavko B. A method for rapid vulnerability assessment of structures loaded by outside blasts. Nucl. Eng. Des., 2017, 239, 1641-1646. 